\title{
Novel molecular targets regulated by tumor suppressors microRNA-1 and microRNA-133a in bladder cancer
}

\author{
TAKESHI YAMASAKI ${ }^{1}$, HIROFUMI YOSHINO ${ }^{1}$, HIDEKI ENOKIDA $^{1}$, HIDEO HIDAKA $^{1}$, TAKESHI CHIYOMARU ${ }^{1}$, \\ NIJIRO NOHATA ${ }^{2}$, TAKASHI KINOSHITA ${ }^{2}$, MIKI FUSE $^{2}$, NAOHIKO SEKI $^{2}$ and MASAYUKI NAKAGAWA ${ }^{1}$ \\ ${ }^{1}$ Department of Urology, Graduate School of Medical and Dental Sciences, Kagoshima University, Kagoshima; \\ ${ }^{2}$ Department of Functional Genomics, Graduate School of Medicine, Chiba University, Chiba, Japan
}

Received November 27, 2011; Accepted January 26, 2012

DOI: $10.3892 /$ ijo.2012.1391

\begin{abstract}
Our expression signatures of human cancer including bladder cancer (BC) revealed that the expression of microRNA-1 $(m i R-1)$ and microRNA-133a (miR-133a) is significantly reduced in cancer cells. In the human genome, $m i R-1$ and $m i R-133 a$ are located on the same chromosomal region (miR-1-2 and $m i R$ $133 a-1$ on $18 \mathrm{q} 11.2$, and $m i R-1-1$ and $m i R-133 a-2$ on $20 \mathrm{q} 13.33$ ) called cluster. In this study, we identified the novel molecular targets commonly regulated by $m i R-1$ and $m i R-133 a$ in $\mathrm{BC}$. Genome-wide molecular target search and luciferase reporter assays showed that prothymosin- $\alpha$ (PTMA) and purine nucleoside phosphorylase (PNP) are directly regulated by $m i R-1$ and $m i R-133 a$. Silencing of these two genes significantly inhibited cell proliferation and invasion, and increased apoptosis in BC cells. Immunohistochemistry showed that PTMA expression levels were significantly higher in $\mathrm{BC}$ compared to normal bladder epitheliums. PTMA and PNP were identified as new target genes regulated by the $m i R-1$ and $m i R-133 a$ cluster in $\mathrm{BC}$. These genes may function as oncogenes contributing to cell proliferation and invasion in $\mathrm{BC}$. Tumor suppressive $m i R-1$ and miR-133a-mediated novel molecular targets may provide new insights into the potential mechanisms of $\mathrm{BC}$ oncogenesis.
\end{abstract}

\section{Introduction}

Bladder cancer (BC) is the fourth most common tumor diagnosed and the second most common cancer of the genitourinary tract in the United States (1). Though there have been significant advances in treatment, including surgical technique and adjuvant chemotherapy, approximately $70 \%$ of first diagnosed $\mathrm{BC}$ recurs after treatment, and $10-15 \%$ of recurrent tumors proceed to muscle invasion and metastasis (2). Therefore, it is

Correspondence to: Dr Hideki Enokida, Department of Urology, Graduate School of Medical and Dental Sciences, Kagoshima University, 8-35-1 Sakuragaoka, Kagoshima 890-520, Japan

E-mail: enokida@m.kufm.kagoshima-u.ac.jp

Key words: bladder cancer, microRNA, miR-1, miR-133, prothymosin- $\alpha$, purine nucleoside phosphorylase crucial to find a new strategy for BC diagnosis and treatment based on novel molecular networks in BC oncogenesis.

MicroRNAs (miRNAs) are a class of small non-coding RNA molecules of 20-22 nucleotides which function as negative regulators (cleavage or translational repression) of gene expression by directly bind to specific mRNAs (3). Many studies have shown that miRNAs regulate diverse cellular processes involved in differentiation, apoptosis, cell proliferation, metabolism, immunity, and development (4). Furthermore, recent studies suggest that miRNAs are associated with the development of various cancers: some miRNAs have an oncogenic function, while others have a tumor suppressive function (5).

$m i R-1$ and $m i R-133 a$ are located on the same chromosomal regions, in a so-called 'cluster', and there are two different chromosomal loci that harbor $m i R-1$ and $m i R-133 a$ clusters ( $m i R-1-2$ and $m i R-133 a-1$ on $18 \mathrm{q} 11.2$, and $m i R-1-1$ and $m i R-133 a-2$ on 20q13.33). Since thousands of miRNAs have been discovered in different species, 247 in human miRNAs have been found to occur in 64 clusters at an inter-miRNA distance of less than 5000 bp (6). In recent studies, $m i R-17 /-92$ and $m i R-221 /-222$ clusters were reported to be over-expressed and to be associated with oncogenic function in several malignancies $(7,8)$. On the other hand, $m i R-15 /-16$ cluster was reported to be low-expressed and function as tumor suppressor in several malignancies. And miR-15/-16 cluster targets oncogenes such as BCL2, MCL1, $C C N D 1$, and $W N T 3 A$, and induces apoptosis and inhibits cell proliferation (9). It is important to analyze the function of miRNA cluster in oncology.

The expression of $m i R-1$ and $m i R-133 a$ has been reported to be down-regulated in various cancers, and these miRNAs might have tumor suppressive functions (4,10-13). We previously reported that $m i R-1$ and $m i R-133 a$ directly regulated oncogenic LASP1 and TAGLN2 genes in human BC $(14,15)$. In our previous gene expression profiles in $m i R-1$ - and $m i R$ - $133 a$-transfected $\mathrm{BC}$ cell lines, prothymosin- $\alpha$ (PTMA) and purine nucleoside phosphorylase $(P N P)$ were the second and third candidate gene, having these miRNAs as the common target.

In this study, we focused on these two genes (PTMA and $P N P$ ), and hypothesized that $m i R-1$ and $m i R-133 a$ directly regulate oncogenic PTMA and $P N P$ in $\mathrm{BC}$. We performed a luciferase reporter assay to determine whether PTMA and PNP mRNA are actually targeted by $m i R-1$ and $m i R-133 a$ and a loss of function study using siRNA to elucidate the functional roles 
of PTMA and PNP in BC. We also performed immunohistochemistry to investigate differences in the protein-expression between clinical BC specimens and normal bladder epitheliums (NBEs).

\section{Materials and methods}

BC cell lines and cell culture. We used two human BC cell lines: BOY, which was established in our laboratory from an Asian male patient aged 66 and diagnosed with stage III BC with lung metastasis (16); and T24, which was invasive and obtained from the American Type Culture Collection. These cell lines were maintained in a minimum essential medium (MEM) supplemented with $10 \%$ fetal bovine serum in a humidified atmosphere of $5 \% \mathrm{CO}_{2}$ and $95 \%$ air at $37^{\circ} \mathrm{C}$.

Prediction of miRNA candidates targeting PTMA and PNP $m R N A$. We used the TargetScan (release 5.1, http://www. targetscan.org/) to search for the predicted miRNA candidates targeting PTMA and PNP mRNA. We also investigated the target sites where the seed regions of these miRNAs bind. The sequences of the predicted mature miRNAs were confirmed by referring to miRBase (release 16.0, Sept 2010; http://microrna. sanger.ac.uk/).

RNA extraction. Total RNA was extracted from frozen fresh tissues using an Isogen ${ }^{\mathrm{TM}}$ kit (Nippon Gene, Tokyo, Japan) in accordance with the manufacturer's protocol. The integrity of the RNA was checked with an RNA 6000 Nano Assay Kit and a 2100 Bioanalyzer ${ }^{\mathrm{TM}}$ (Agilent Technologies, Santa Clara, CA, USA).

Quantitative real-time RT-PCR. TaqMan probes and primers for PTMA (P/N: Hs02339492_g1; Applied Biosystems, Foster City, CA, USA) and PNP (P/N: Hs00165367_m1: Applied Biosystems) were assay-on-demand gene expression products. All reactions were performed in duplicate, and a negative-control lacking cDNA was included. We followed the manufacturer's protocol for the PCR conditions. We used human GUSB $(\mathrm{P} / \mathrm{N}$ : Hs99999908_m1; Applied Biosystems) to normalize the data for quantification of PTMA and PNP mRNA, and we used the $\Delta \Delta \mathrm{C}_{\mathrm{t}}$ method to calculate the fold change. As a control RNA, premium total RNA was used from normal human bladder (Clontech, Mountain View, CA, USA).

Mature miRNA and siRNA transfection. As described elsewhere (16), the BC cell lines were transfected with Lipofectamine ${ }^{\mathrm{TM}}$ RNAiMAX transfection reagent (Invitrogen, Carlsbad, CA, USA) and Opti-MEM ${ }^{\mathrm{TM}}$ (Invitrogen) with $10 \mathrm{nM}$ of mature miRNA molecules. Pre-miR ${ }^{\mathrm{TM}}$ and negative-control miRNA (Applied Biosystems) were used in the gain-of-function experiments, whereas PTMA and PNP siRNA (P/N: s11497; Applied Biosystems, cat no. HSS107263 and HSS181558 Invitrogen) and negative control siRNA(D-001810-10; Thermo Fisher Scientific, Waltham, MA, USA) were used in the loss-of-function experiments. Cells were seeded in a $10-\mathrm{cm}$ dish for protein extraction ( $8 \times 10^{5}$ per dish), a 6 -well plate for apoptosis $\left(1 \times 10^{5}\right.$ per well), in a 24-well plate for the mRNA extraction, matrigel invasion assay, and luciferase reporter assay $\left(5 \times 10^{4}\right.$ per well), and in a 96-well plate for the XTT assay $(3,000$ per well).
Cell proliferation and invasion assays. Cell proliferation was determined by using an XTT assay (Roche Applied Sciences, Tokyo, Japan) performed according to the manufacturer's instructions. A cell invasion assay was carried out using modified Boyden Chambers consisting of transwell-precoated matrigel membrane filter inserts with $8-\mathrm{mm}$ pores in 24-well tissue culture plates (BD Biosciences, Bedfold, MA). MEM containing $10 \%$ foetal bovine serum in the lower chamber served as a chemoattractant, as described previously (10). All experiments were performed in triplicate.

Apoptosis analysis. BC cell lines transiently transfected with transfection reagent si-control, or si-PTMA and si-PNP in 6-well tissue culture plates, as described earlier, were harvested $72 \mathrm{~h}$ after transfection by trypsinization and washed in cold PBS. Double staining with FITC-Annexin $\mathrm{V}$ and propidium iodide (PI) was carried out using the FITC Annexin V Apoptosis Detection Kit (BD Biosciences) according to the manufacturer's recommendations and immediately analyzed within an hour by flow cytometry (FACScan ${ }^{\circledR}$; BD Biosciences). Cells were discriminated into viable cells, dead cells, early apoptotic cells, and apoptotic cells by using the CellQuest software (BD Biosciences), and then the percentages of early apoptotic and apoptotic cells from each experiment were compared. These experiments were done in triplicate.

Caspase-3/7 activity assays. Caspase-3/7 activity was measured by CellEvent ${ }^{\mathrm{TM}}$ Caspase-3/7 Green Detection Reagent (Invitrogen). The BC cell lines were grown in 96-well plates and were transfected with si-RNAs as described above. After $72 \mathrm{~h}$, $5 \mu \mathrm{M}$ caspase-3/7 reagents were added to each well and incubated for $30 \mathrm{~min}$. Fluorescence was then measured and recorded for each well. For densitometric analysis, the expression level of the sum of fluorescent particles was measured with ImageJ software (http://rsb.info.nih.gov/ij).

Immunohistochemistry in tissue microarray. A tissue microarray of bladder cancer samples was obtained from Biomax, inc. (BL1002; Rockville, MD, USA). Detailed information on all tumor specimens can be found at http://www.biomax.us/ index.php. Patient characteristics are summarized in Table II. The tissue microarray was immunostained following the manufacturer's protocol with an UltraVision Detection System (Thermo Scientific). The primary mouse monoclonal antibodies against PTMA (Alexis, San Diego, CA) and the primary rabbit polyclonal antibodies against PNP (Sigma-Aldrich) were diluted 1:300 and 1:450. The slides were treated with biotinylated goat anti-rabbit. Diaminobenzidinehydrogen peroxidase was the chromogen, and the counterstaining was done with $0.5 \%$ hematoxylin. The positivity of endothelia and myofibroblasts served as an inner positive control. The immunostaining result was evaluated using the scoring method described previously (17). Each case was scored on the basis of the intensity and area of staining. The intensity of staining was graded on the following scale: 0 , no staining; $1+$, mild staining; $2+, 30-60 \%$ stained positive; $3+,>60 \%$ stained positive. A combined staining score (intensity + extension) of $<2$ was low expression, a score between 3 and 4 was moderate expression, and a score between 5 and 6 was high expression. All staining scores were averages of duplicate experiments, and all samples were independently scored by two 
Table I. Down-regulated genes in $m i R-1$ - and $m i R$ - $133 a$-transfected T24 cell line in gene expression profile.

\begin{tabular}{|c|c|c|c|c|c|c|}
\hline \multirow{2}{*}{$\begin{array}{l}\text { Entrez } \\
\text { Gene ID }\end{array}$} & \multirow[b]{2}{*}{ Symbol } & \multicolumn{3}{|c|}{ Fold change ( $\log 2$ ratio) } & \multicolumn{2}{|c|}{ Target sites } \\
\hline & & $m i R-1$ & $m i R-133 a$ & Average & $m i R-1$ & $m i R-133 a$ \\
\hline 8407 & TAGLN2 & -3.33 & -2.81 & -3.07 & + & + \\
\hline 23446 & SLC44A1 & -3.69 & -1.22 & -2.46 & + & - \\
\hline 80150 & ASRGL1 & -1.54 & -3.01 & -2.28 & + & - \\
\hline 5757 & PTMA & -2.04 & -2.50 & -2.27 & + & + \\
\hline 4860 & PNP & -2.54 & -1.75 & -2.15 & + & + \\
\hline 26150 & RIBC2 & -1.45 & -2.72 & -2.09 & - & - \\
\hline 63827 & BCAN & -1.15 & -2.97 & -2.06 & - & - \\
\hline 29956 & LASS2 & -1.11 & -2.85 & -1.98 & + & + \\
\hline 7170 & TPM3 & -1.56 & -2.35 & -1.96 & + & + \\
\hline 7095 & SEC62 & -1.40 & -2.41 & -1.91 & + & - \\
\hline 23531 & MMD & -2.08 & -1.51 & -1.80 & + & - \\
\hline 23603 & CORO1C & -1.88 & -1.67 & -1.78 & + & + \\
\hline 55276 & PGM2 & -1.90 & -1.64 & -1.77 & + & - \\
\hline 201895 & C4orf34 & -1.50 & -1.98 & -1.74 & + & + \\
\hline 11167 & FSTL1 & -1.23 & -2.16 & -1.70 & + & - \\
\hline 81831 & NETO2 & -1.90 & -1.47 & -1.69 & + & - \\
\hline 79850 & FAM57A & -2.05 & -1.28 & -1.67 & + & + \\
\hline 23607 & CD2AP & -1.22 & -1.95 & -1.59 & + & + \\
\hline 55653 & BCAS4 & -1.57 & -1.55 & -1.56 & - & - \\
\hline 11168 & PSIP1 & -1.54 & -1.51 & -1.53 & - & - \\
\hline 55179 & FAIM & -1.36 & -1.52 & -1.44 & + & + \\
\hline 79841 & AGBL2 & -1.14 & -1.74 & -1.44 & - & - \\
\hline 25927 & CNRIP1 & -1.56 & -1.22 & -1.39 & + & - \\
\hline 5819 & PVRL2 & -1.37 & -1.22 & -1.30 & + & - \\
\hline 57542 & KLHDC5 & -1.57 & -1.02 & -1.30 & + & + \\
\hline 63929 & XPNPEP3 & -1.25 & -1.29 & -1.27 & + & - \\
\hline 57171 & DOLPP1 & -1.15 & -1.36 & -1.26 & + & + \\
\hline 5780 & PTPN9 & -1.11 & -1.31 & -1.21 & + & - \\
\hline 26999 & CYFIP2 & -1.04 & -1.33 & -1.19 & + & + \\
\hline 23178 & PASK & -1.11 & -1.22 & -1.17 & + & - \\
\hline 11147 & HHLA3 & -1.15 & -1.16 & -1.16 & + & - \\
\hline 523 & ATP6V1A & -1.01 & -1.22 & -1.12 & + & + \\
\hline 64924 & SLC30A5 & -1.00 & -1.04 & -1.02 & - & + \\
\hline
\end{tabular}

of the authors (T. Yamasaki and H. Yoshino) who were blinded to the patient status.

Statistical analysis. The relationship between two variables and numerical values was analyzed using the Mann-Whitney $\mathrm{U}$ test, and the relationship between three variables and the numerical values was analyzed using the Bonferroni-adjusted Mann-Whitney U test. Expert Stat View analysis software (ver.4; SAS institute Inc., Cary, NC) was used in both analyses. In the comparison of three variables, a non-adjusted statistical level of significance of $\mathrm{P}<0.05$ corresponded to the Bonferroni-adjusted level of $\mathrm{P}<0.0167$.

\section{Results}

Gene expression profile identifying down-regulated genes in miR-1 and miR-133a transfectants. In our previous studies, we performed gene expression analyses using $m i R-1$ transfectants (BOY and T24) and $m i R-133 a$ transfectants (KK47 and T24) [the gene expression omnibus (GEO) accession No. GSE24782 and GSE19717] $(11,15)$. In this study, we reconstructed a list for common target genes of $m i R-1$ and $m i R-133 a$ by using the miRNA transfected-T24, because T24 was commonly adapted in these analyses. We found a total of 33 genes were downregulated $<-2.0$-fold in both transfectants in comparison with their controls. Among them, TAGLN2, PTMA and PNP were the top three down-regulated genes that had putative target sites of both miR-1 and miR-133a in their 3'UTR (Table I). We previously reported that TAGLN2 was targeted by $m i R-1$ and $m i R-133 a$. Therefore, we focused on the PTMA and PNP genes as promising candidates targeted by both $m i R-1$ and $m i R-133 a$.

PTMA and PNP mRNA expression in BC cell lines and PTMA and PNP silencing by miR-1 and miR-133a transfection. The 
A

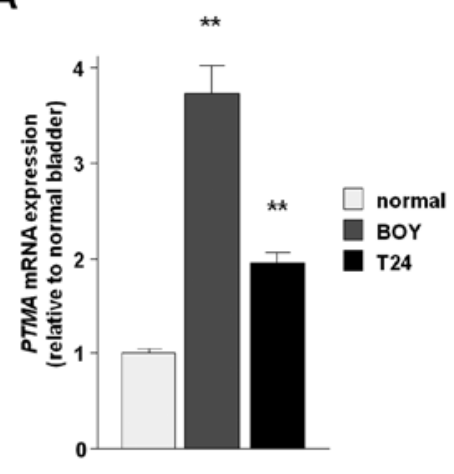

C

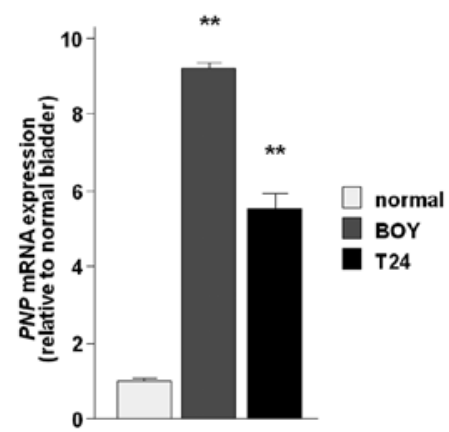

B

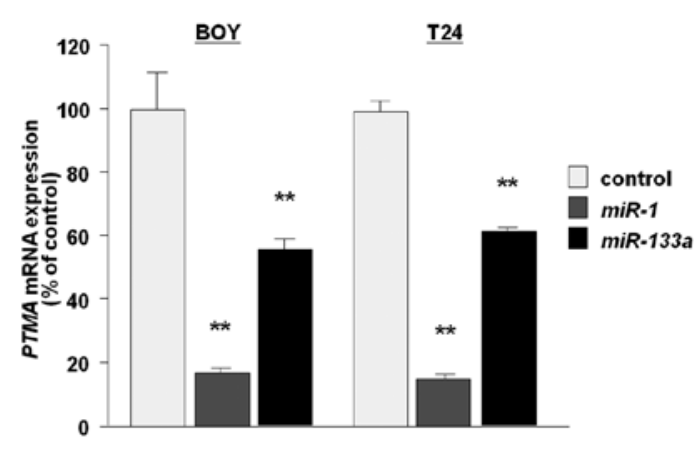

D

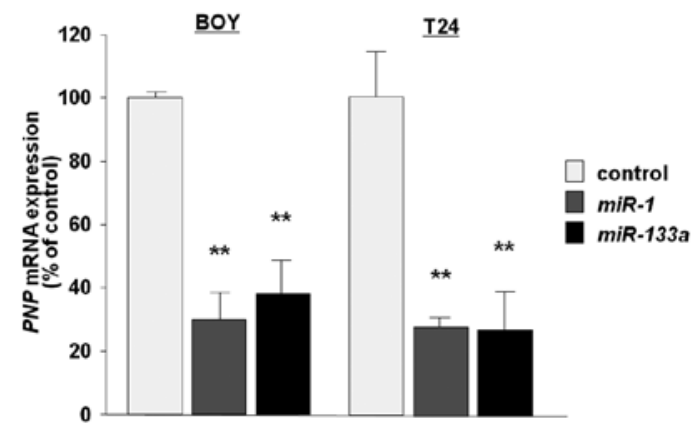

Figure 1. mRNA expression in BC cell lines, and $m i R-1$ and $m i R-133 a$ transfectants (A) mRNA expression of $P T M A$ in the BOY and T2 4 cell lines and the normal human bladder RNA. (B) PTMA mRNA expression after 24-h transfection with $10 \mathrm{nM}$ of the miRNA ( $m i R-1$ and $m i R-133 a$ ) in the BOY and T24 cell lines. The mRNA expression level of PTMA was repressed in the transfectants. (C) mRNA expression of $P N P$ in the BOY and T24 cell lines and the normal human bladder RNA. (D) PNP mRNA after 24-h transfection with $10 \mathrm{nM}$ of the miRNA ( $m i R-1$ and $m i R-133 a$ ) in the BOY and T24 cell lines. The mRNA expression level of $P N P$ was also repressed in the transfectants.

Table II. Patient characteristics.

BC specimens $(n=68)$

Median age (range)

Gender

Male 54

Female

Histologic grade

$\mathrm{G} 1+\mathrm{G} 2$

G3

Unknown

Tumor stage

T1

T2

T3

T4

NBEs (urocystitis tissues) $(\mathrm{n}=17)$.

quantitative real-time RT-PCR analysis showed that the PTMA mRNA expressions in the BOY and T24 cell lines were respec- tively higher than that in normal human bladder RNA $(\mathrm{P}<0.0001$, Fig. 1A). The PTMA mRNA expression was markedly downregulated in the $m i R-1$ and $m i R-133 a$ transfectants compared with the control in the BOY and T24 cell lines $(\mathrm{P}<0.0001$, Fig. 1B). The quantitative real-time RT-PCR analysis showed that the PNP mRNA expressions in the BOY and T24 cell lines were respectively higher than in normal human bladder RNA $(\mathrm{P}<0.0001$, Fig. 1C). The PNP mRNA expression was markedly down-regulated in the $m i R-1$ and $m i R-133 a$ transfectants compared with the control in BOY and T24 cell lines $(\mathrm{P}<0.0001$, Fig. 1D).

PTMA and PNP as a target of post-transcriptional repression by $m i R-1$ and $m i R-133 a$. We performed a luciferase reporter assay to determine whether PTMA and PNP mRNA have target sites for $m i R-1$ and $m i R-133 a$. We used a vector encoding fulllength 3'UTR of PTMA and PNP mRNA and found that the luminescence intensity was significantly reduced in the $m i R-1$ and $m i R-133 a$ transfectants, suggesting that these genes have actual binding sites of $m i R-1$ and $m i R-133 a$ (P<0.0001, Fig. 2).

Effect of PTMA knockdown on cell proliferation and invasion activity, and apoptosis through caspase-3/7 activation in $B C$ cell lines. To examine the functional role of PTMA, we performed loss-of-function studies using si-PTMA-transfected BOY and T24 cell lines. The PTMA mRNA expression was 
A

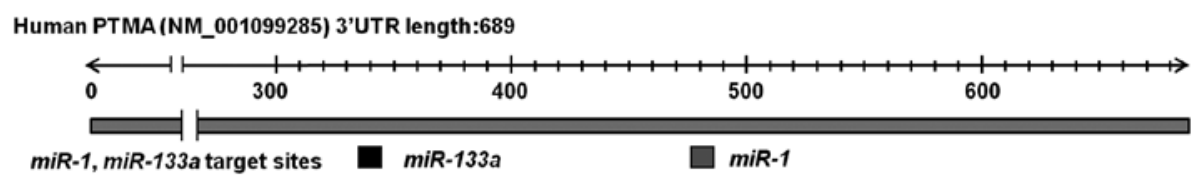

position $476-482$ of $3^{\prime}$ UTR

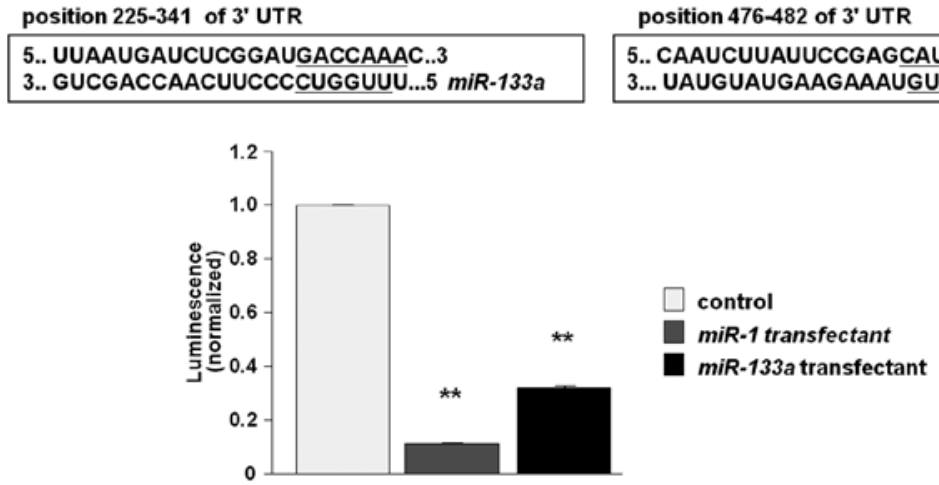

B

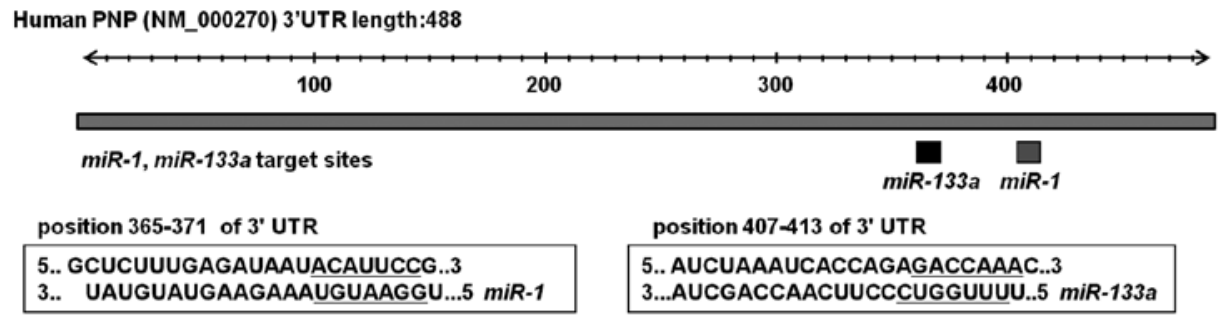

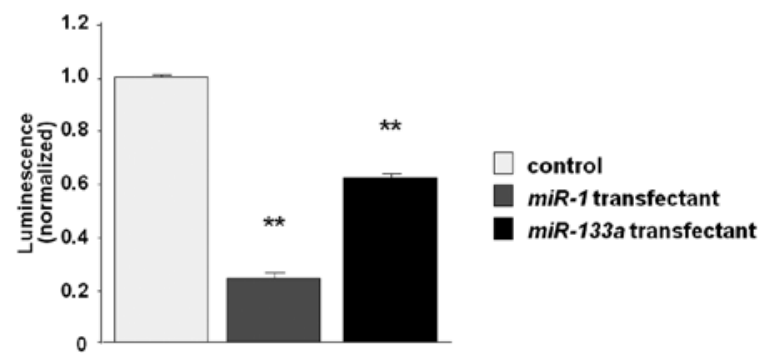

Figure 2. MiR-1 and miR-133a binding sites in 3'-UTR of mRNA and luciferase reporter assay. (A and B, upper) $M i R-1$ and $m i R-133 a$ binding sites in 3 '-UTR of $P T M A$ and $P N P$ mRNA. (A and B, lower) luciferase reporter assay using the vector encoding full-length $3^{\prime}-\mathrm{UTR}$ of $P T M A$ and $P N P$ mRNA. The Renilla luciferase values were normalized by the firefly luciferase values. ${ }^{* *} \mathrm{P}<0.0001$.

markedly repressed by the si-PTMA transfection $(\mathrm{P}<0.0001$, Fig. 3A). The XTT assay revealed significant cell proliferation inhibition in the si-PTMA transfectants in comparison with the si-control transfectants (\% of cell viability; BOY, $68.5 \pm 6.0$ and $100.0 \pm 1.3$, respectively, $\mathrm{P}=0.0039 ; \mathrm{T} 24,87.1 \pm 7.7$ and $100.0 \pm 2.9$, respectively, $\mathrm{P}=0.0106$; Fig. $3 \mathrm{~B}$ ). The matrigel invasion assay demonstrated that the number of invading cells was significantly decreased in the si-PTMA transfectants compared with the si-control transfectants (\% of cell invasion; BOY, 35.7 \pm 3.9 and $100.0 \pm 10.0$, respectively, $\mathrm{P}<0.0001 ; \mathrm{T} 24,66.2 \pm 6.0$ and $100.0 \pm 5.3$, respectively, $\mathrm{P}=0.0013$; Fig. 3C). Cell apoptosis in si-PTMA transfectants was detected using flow cytometry. The apoptotic cell fractions (early apoptotic and late apoptotic, bottom right and upper right quadrants, respectively) were greater in the si-PTMA transfectants than the si-control transfec- tants $72 \mathrm{~h}$ after transfection (relative to control; BOY, $1.86 \pm 0.23$ and $1.00 \pm 0.07$, respectively, $\mathrm{P}=0.0090 ; \mathrm{T} 24,1.86 \pm 0.29$ and $1.00 \pm 0.04$, respectively, $P=0.0090$; Fig. 3D). Caspase- $3 / 7$ activity assays showed that fluorescence intensity was also markedly increased in the si-PTMA transfectants compared with the si-control transfectants (relative to control; BOY, $8.47 \pm 2.86$ and $1.00 \pm 0.21$, respectively, $\mathrm{P}=0.0012 ; \mathrm{T} 24,9.56 \pm 2.17$ and $1.00 \pm 0.37$, respectively, $\mathrm{P}=0.0023$; Fig. 3E).

Effect of PNP knockdown on cell proliferation, migration and invasion activity in $B C$ cell lines. To examine the functional role of PNP, we performed loss-of-function studies using si-PNPtransfected BOY and T24 cell lines. The PNP mRNA expression was markedly repressed by the si-PNP transfection $(\mathrm{P}<0.0001$, Fig. 4A). The XTT assay revealed significant cell proliferation 
A

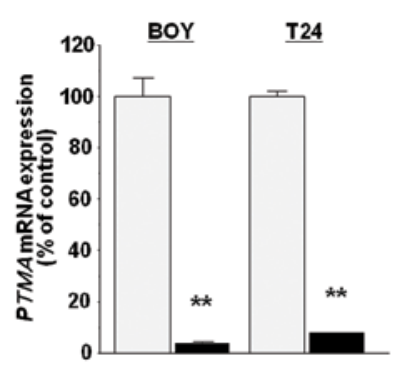

C
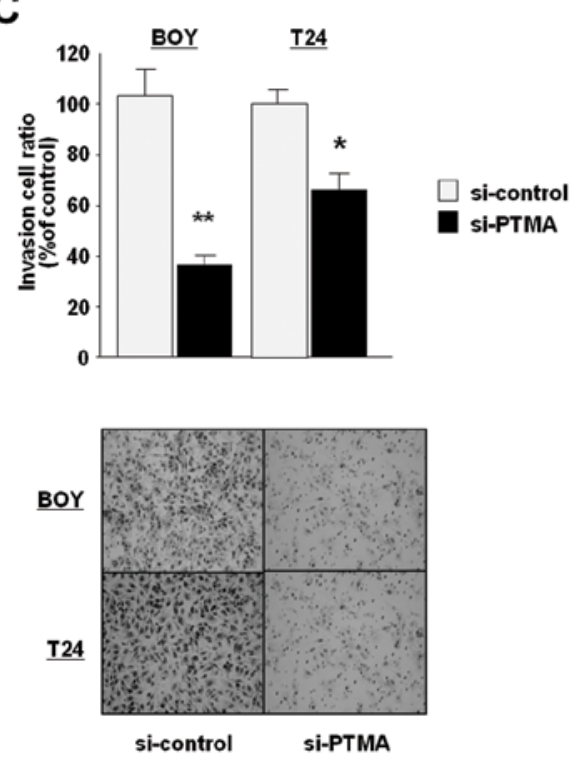

$\mathbf{E}$
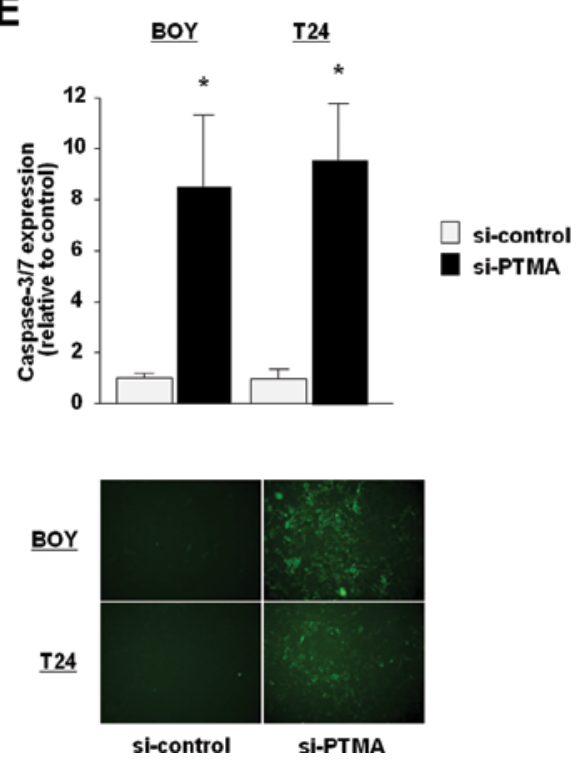

inhibition in the si-PNP transfectants in comparison with the si-control transfectants (\% of cell viability; BOY, $54.4 \pm 0.9$ and $100.0 \pm 2.4$, respectively, $\mathrm{P}=0.0090 ; \mathrm{T} 24,74.6 \pm 2.7$ and $100.0 \pm 2.2$,
B
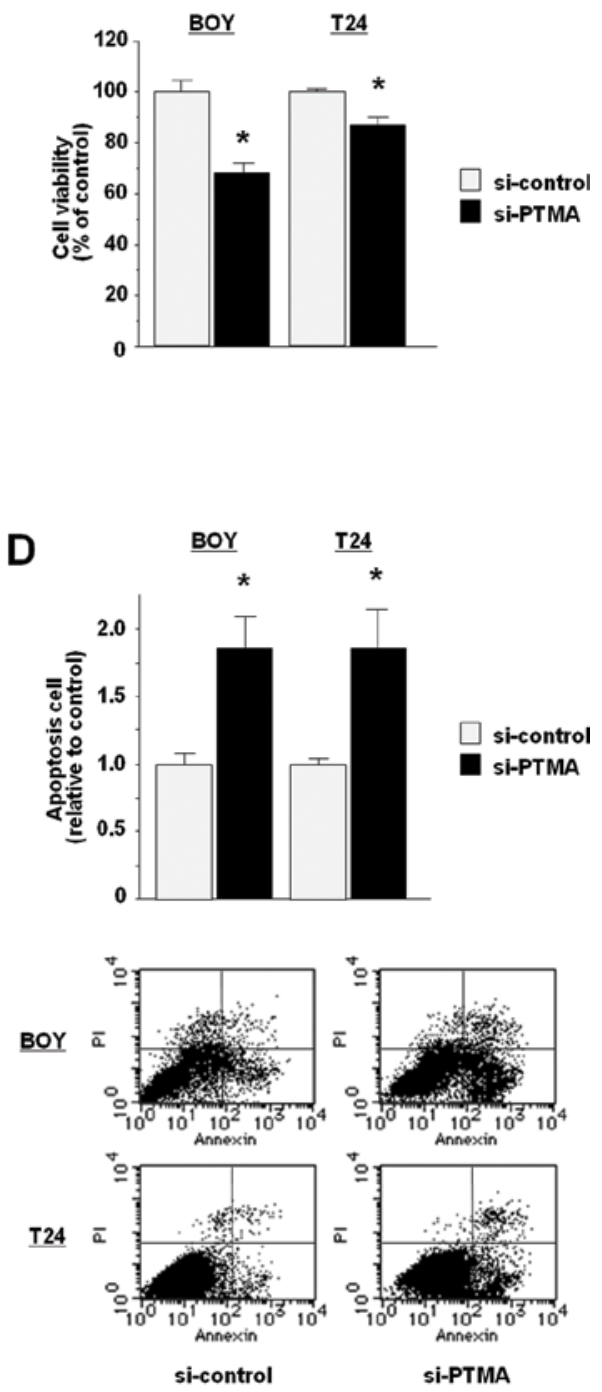

Figure 3. Loss of function study, apoptosis assay, and caspase-3/7 activity assay in si-PTMA transfectants. (A) PTMA mRNA expression after 24-h transfection with $10 \mathrm{nM}$ of si-PTMA. (B-D) PTMA knockdown effects on BC cell viability by si-PTMA. (B) Cell proliferation determined by the XTT assay; (C) Cell invasion activity as determined by the matrigel invasion assay; (D) Apoptosis assay as determined by flow cytometry in BOY and T24 cell. Early apoptotic cells can be seen in the bottom right quadrant, and late apoptotic cells are in the upper right. The normalized ratio of the apoptosis assay is shown in the histogram. ${ }^{*} \mathrm{P}<0.05$. ${ }^{* *} \mathrm{P}<0.0001$. (E) Caspase-3/7 activity was measured by fluorescence intensity in BOY and T24 cell lines transfected with si-PTMA. ${ }^{*} \mathrm{P}<0.05$. respectively, $\mathrm{P}=0.0090$; Fig. 4B). The matrigel invasion assay demonstrated that the number of invading cells was significantly decreased in the si-PNP transfectants compared with the 
A

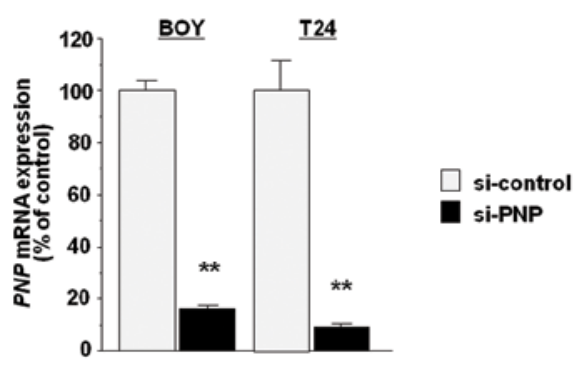

C

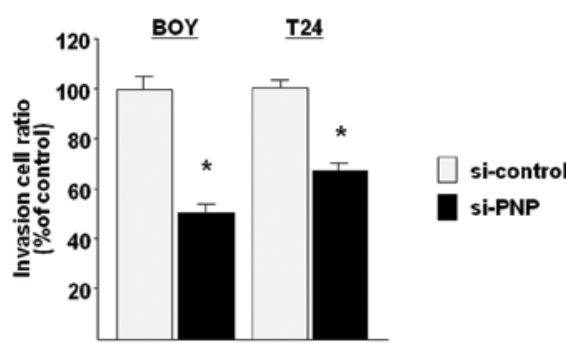

BOY

T24

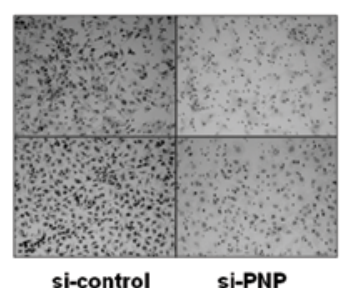

E
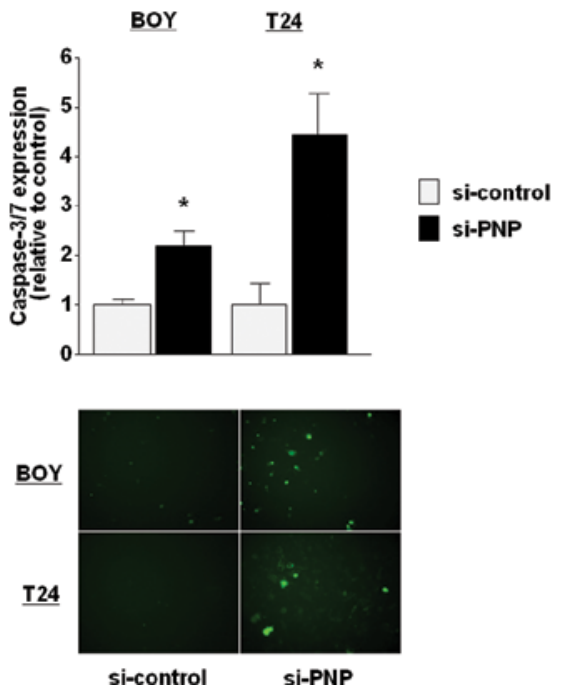

B

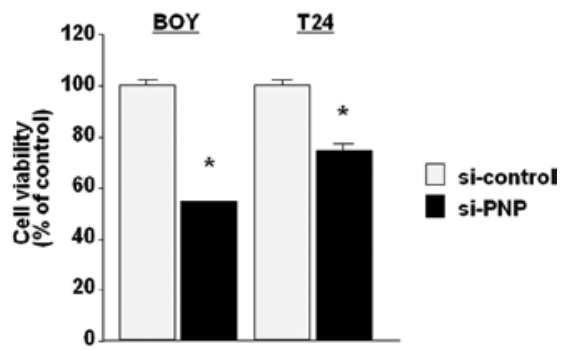

D
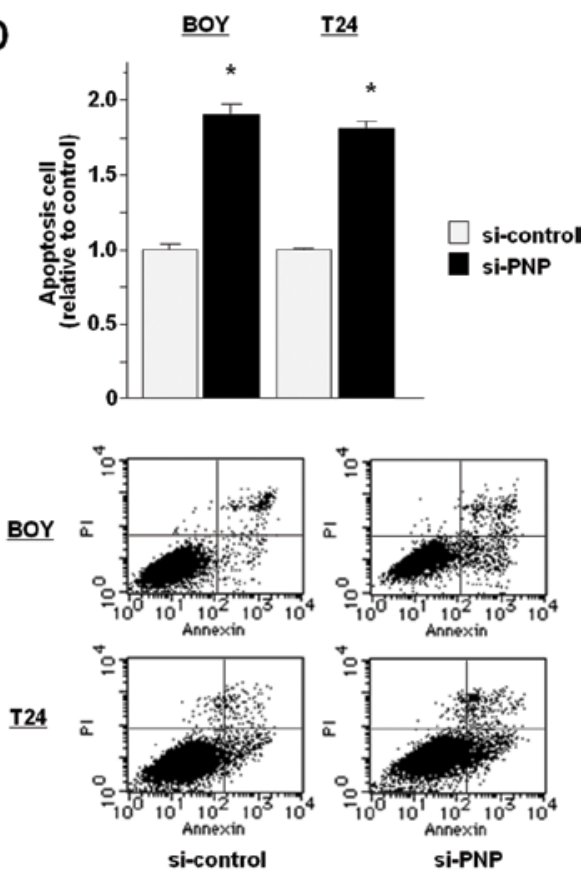

Figure 4. PNP mRNA expression and loss-of-function study in si-PNP transfectants. (A) $P N P$ mRNA expression after 24-h transfection with $10 \mathrm{nM}$ of si-PNP. (B-D) PNP-knockdown effects on BC cell viability by si-RNA. (B) Cell proliferation determined by the XTT assay; and (C) cell invasion activity determined by the matrigel invasion assay were evaluated in BOY and T24 cell lines transfected with si-PNP. ${ }^{*} \mathrm{P}<0.05,{ }^{* *} \mathrm{P}<0.0001$. (D) Apoptosis assay as determined by flow cytometry in BOY and T24 cell. Early apoptotic cells can be seen in the bottom right quadrant, and late apoptotic cells are in the upper right. The normalized ratio of the apoptosis assay is shown in the histogram ${ }^{*} \mathrm{P}<0.05$. ${ }^{* *} \mathrm{P}<0.0001$. (E) Caspase-3/7 activity was measured by fluorescence intensity in BOY and T24 cell lines transfected with si-PNP. ${ }^{*} \mathrm{P}<0.05$.

si-control transfectants (\% of cell invasion; BOY, $50.3 \pm 3.3$ and $100.0 \pm 5.2$, respectively, $\mathrm{P}=0.0080 ; \mathrm{T} 24,65.4 \pm 7.2$ and $100.0 \pm 2.7$, respectively, $\mathrm{P}=0.0016$; Fig. 4 C). Cell apoptosis in si-PNP trans- fectants was detected using flow cytometry. The apoptotic cell fractions (early apoptotic and late apoptotic, bottom right and upper right quadrants, respectively) were greater in the si-PTMA 
A

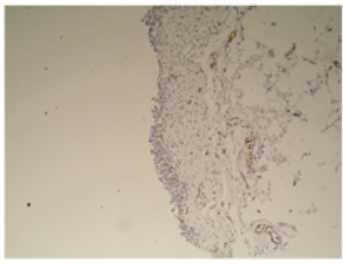

NBE \#1

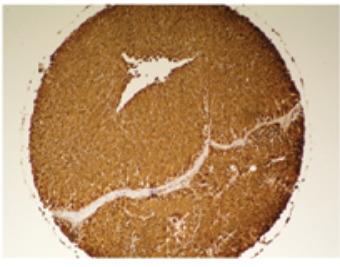

BC \#1 (G1)

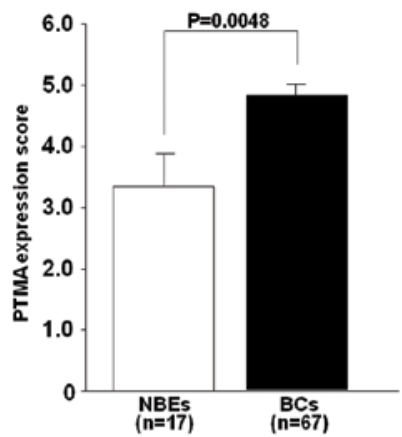

B

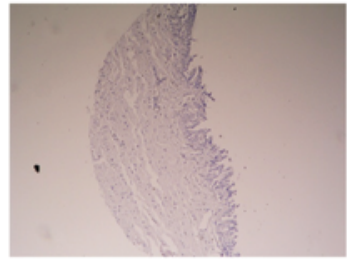

NBE\#1

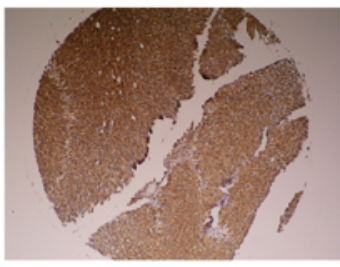

BC\#1 (G1)

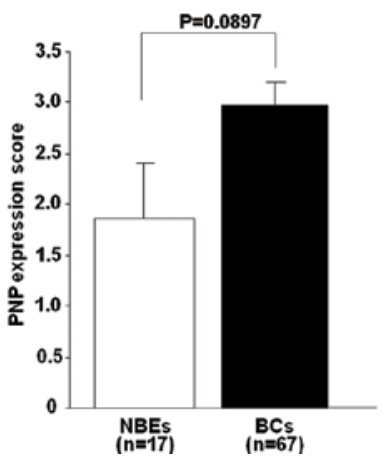

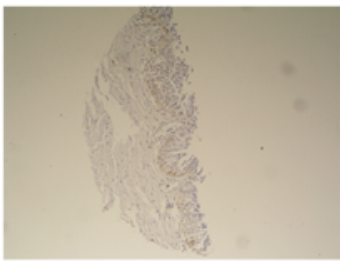

NBE\#2

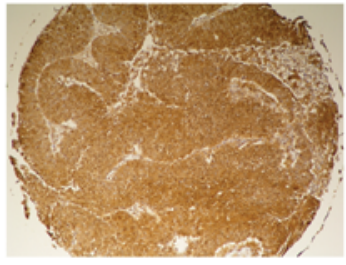

BC \#2 (G2)

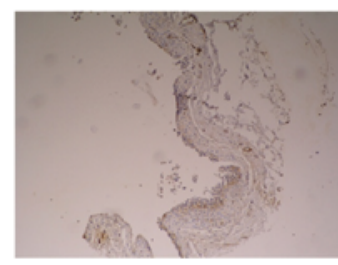

NBE\#3

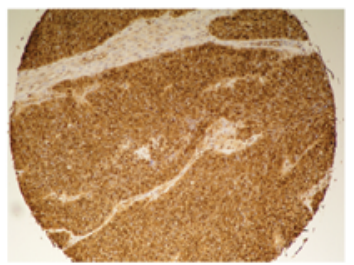

BC \#3 (G3)

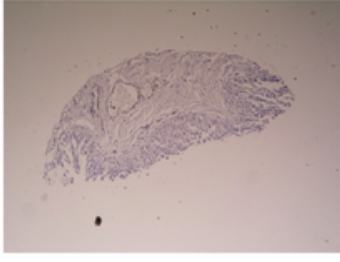

NBE \#2

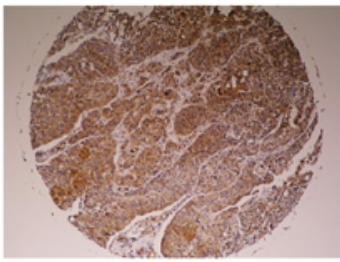

BC \#2 (G2)

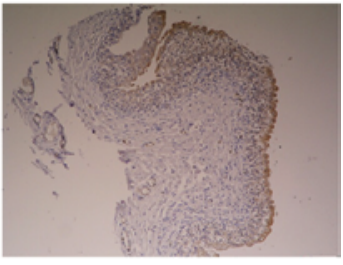

NBE \#3

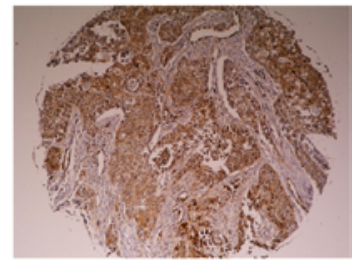

$B C \# 3(\mathbf{G})$

Figure 5. Immonohistochemical staining of PTMA and PNP in tissue microarray. (A) Immunohistochemical staining of PTMA in tissue specimens (magnification x100). (A, upper) Negative staining in normal bladder epitheliums (NBEs) with urocystis tissue. (A, middle) Positively stained tumor lesions (grade 1, T1NOM0; grade 2, T3NOM0; and grade 3, T2NOM0). (A, lower) Scoring of PTMA expression. There was a significant difference in the expression score of PTMA of 68 BCs in comparison with 17 NBEs. (B) Immunohistochemical staining of PNP in tissue specimens (magnification $\mathrm{x} 100$ ). (B, upper) Negative staining in normal bladder epitheliums (NBEs) with urocystis tissue. (B, middle) Positively stained tumor lesions (grade 1, T1NOM0; grade 2, T3NOM0; and grade 3, T2NOM0). (B, lower) Scoring of $\mathrm{PNP}$ expression. There was a trend but no significant difference in the expression score of PNP of 68 BCs in comparison with 17NBEs.

transfectants than the si-control transfectants $72 \mathrm{~h}$ after transfection (relative to control; BOY, $1.89 \pm 0.09$ and $1.00 \pm 0.03$, respectively, $\mathrm{P}=0.0090 ; \mathrm{T} 24,1.81 \pm 0.05$ and $1.00 \pm 0.01$, respec- tively, $\mathrm{P}=0.0090$; Fig. 4D). Caspase-3/7 activity assays showed that fluorescence intensity was also markedly increased in the si-PNP transfectants compared with the si-control transfectants 
(relative to control; BOY, $2.20 \pm 0.32$ and $1.00 \pm 0.13$, respectively, $\mathrm{P}=0.0495 ; \mathrm{T} 24,4.43 \pm 0.86$ and $1.00 \pm 0.43$, respectively, $\mathrm{P}=0.0495$; Fig. 4E).

Immunohistochemistry in tissue microarray. Representative immunohistochemistry of PTMA and PNP is shown in Fig. 5. The PTMA was strongly expressed in BCs compared with NBEs (Fig. 5A, upper and middle). The expression score of tumors was significantly higher than that of NBEs and BCs ( $\mathrm{P}=0.0048$, Fig. 5A, lower). In terms of PNP, faint to modest staining were found in NBEs, whereas strong staining of cytosol and nuclei were found in BCs (Fig. 5B, upper and middle). Immunohistochemical staining revealed that there was a trend but no significant difference in the expression score of PNP between BC specimens and NBEs ( $\mathrm{P}=0.0897$, Fig. 5B, lower). Patient characteristics are summarized in Table II. We found no significant difference between the PTMA and PNP expression score and pathological parameters (tumor stage and grade) of $\mathrm{BC}$ patients.

\section{Discussion}

Our recent miRNA expression signatures revealed that the expression levels of $m i R-1$ and $m i R-133 a$ were significantly reduced in various cancer cells $(15,18-20)$. Interestingly, $m i R-1-1 / m i R-133 a-2$ and $m i R-1-2 / m i R-133 a-1$ are clustered on different chromosomal regions in the human genome, 20q13.33 and 18q11.2, respectively. This fact suggests that these miRNAs have an important function in genome. Therefore we performed functional analyses of these miRNAs by using mature miRNA transfection in BC cells. Restoration of $m i R-1$ or $m i R-133 a$ significantly inhibited cancer cell proliferation, migration and invasion, suggested $m i R-1$ or $m i R-133 a$ function as tumor suppressors in BC (15). The function analysis of $m i R-1$ or $m i R-133 a$ in $\mathrm{BC}$ cells strongly confirmed our previous data of, head and neck squamous cell carcinoma (HNSCC), renal cell carcinoma (RCC) and prostate cancer (PCa) (18-20).

The unique point of the miRNA biogenesis is that one miRNA regulates many protein coding genes in human genome. However, many databases predict the target genes from miRNA sequences, it is still unknown which genes actually control by miRNAs. That is why the future problem is elucidation of the networks of miRNA that regulates protein coding genes in various cells. Based on this view, we sequentially identified tumor suppressive miRNAs that regulate multiple oncogene networks in various cancer cells $(10,11,15,18-20)$.

When we searched previous reports for $m i R-1$ regulated genes, recent studies revealed that $m i R-1$ induced apoptosis through repression of Mcl-1 in lung cancer (4). MiR- 1 also targets $c$-Met in rhabdomyosarcoma (RMS) (13). With regard to $m i R-133 a$, several reports showed that $m i R-133 a$ was lowexpressed in colon cancer, tongue squamous cell carcinoma (SCC), and RMS (21-23). In tongue SCC, miR-133a inhibited cell proliferation and induced apoptosis and directly bound to oncogenic PKM2 (22). Furthermore, miR-133a directly regulated multiple oncogenes such as $C A V I$ and GSTPI and in human SCC $(24,25)$.

From the viewpoint of the $m i R-1$ and $m i R-133 a$ cluster in human cancers, three profiles of genes regulated by both $m i R-1$ and $m i R-133 a$ have been reported, BC, PCa and RMS $(15,20,23)$.
In RMS, the contributions of two miRNAs were investigated by $m i R-1$ and $m i R-133 a$ transfectans in RMS cells (27). According to the report, $m i R-1$ exerts a strong promyogenic influence on these poorly differentiated tumor cells. More recently, we identified both $m i R-1$ and $m i R-133 a$ regulated genes in BC, PCa, HNSCC and RCC by using the same methods. When we compared the three profiles (BC, PCa, HNSCC), the common genes regulated by both $m i R-1$ and $m i R-133 a$ were TAGLN2, PVRL2, C4orf34 and $P N P(18,20)$. Among them, TAGLN2 and $P N P$ were directly regulated by $m i R-1$ and $m i R-133 a$ in $\mathrm{BC}$ and $\mathrm{HNSCC}$ and $\mathrm{PCa}$, respectively $(18,20)$. Further, TAGLN2 is common in four profiles including the profile of RCC (19).

In this study, $P T M A$ and $P N P$ were directly down-regulated by both $m i R-1$ and miR-133a transfectants of BC, and contain $m i R-1$ and $m i R-133 a$ putative binding sites on their 3 'UTR regions. Luciferase reporter assay revealed that these genes were directly regulated by both tumor suppressive $m i R-1$ and miR-133a.

PTMA, a small $(12.5 \mathrm{kDa})$ and highly acidic nuclear protein, is highly conserved and widely distributed in mammalian tissues, and it has been implicated in cell cycle progression, cellular and viral transcription, remodeling of chromatin, and anti-apoptosis $(26,27)$. PTMA has been reported to be associated with cancer progression in the liver, lung, prostate, and bladder (28-31). In this study, PTMA knockdown resulted in $\mathrm{BC}$ cell viability inhibition and induction of apoptosis. Our results were consistent with previous reports that demonstrated the relationship between PTMA expression and apoptosis $(26,30,32)$. Previous studies revealed that PTMA was a negative regulator of apoptosis, like Bcl-2, and inhibited caspase-3 or induced blocking the apoptosome formation $(26,27)$. Our caspase-3/7 activity assay also showed that fluorescence intensity was markedly increased in the si-PTMA transfectant confirming previous reports.

PNP is an enzyme in the purine salvage pathway and is involved in the phosphorolysis of substrates (i.e., inosine/ deoxyinosine, xanthosine/deoxyxanthosine, and guanosine/ deoxyguanosine). These conversions result in the inhibition of DNA synthesis and cell death (33). PNP expressions have previously been associated with the development of cancers, such as maxillary sinus SCC, PCa and leukemia $(18,20,33,34)$. PNP inhibitors, such as forodesine inhibited cell proliferation by activating the apoptotic pathway in leukemia $(33,34)$, and phase I and II trials using these PNP inhibitors are currently underway for patients with leukemia (33). In this study, PNP knockdown resulted in cell viability inhibition and induction of apoptosis in $\mathrm{BC}$, as forodesine in leukemia. In addition, PNP knockdown increased caspase-3/7 activity and induced apoptosis in BC.

In conclusion, down-regulation of $m i R-1$ and $m i R-133 a$ was a frequent event in $\mathrm{BC}$ and these miRNAs function as tumor suppressors. PTMA and $P N P$ were directly regulated by $m i R-1$ and $m i R-133 a$ and oncogenes in BC. Tumor suppressive $m i R-1$ and $m i R-133 a$ mediate novel cancer pathways providing new insights into the potential mechanisms of $\mathrm{BC}$ oncogenesis.

\section{Acknowledgements}

This research was partially supported by the Ministry of Education, Science, Sports, and Culture Grants-in-Aid for Scientific Research (C and young B), 23501298 and 23791764 , 
2011. We thank Ms. Mutsumi Miyazaki for her excellent laboratory assistance.

\section{References}

1. Siegel R, Ward E, Brawley O and Jemal A: Cancer statistics, 2011: the impact of eliminating socioeconomic and racial disparities on premature cancer deaths. CA Cancer J Clin 61: 212-236, 2011.

2. Herr H, Konety B, Stein J, Sternberg CN and Wood DP Jr: Optimizing outcomes at every stage of bladder cancer:do we practice it? Urol Oncol 27: 72-74, 2009.

3. Lagos-Quintana M, Rauhut R, Lendeckel W and Tuschl T: Identification of novel genes coding for small expressed RNAs. Science 294: 853-858, 2001.

4. Nasser MW, Datta J, Nuovo G, Kutay H, Motiwala T, Majumder S, Wang B, Suster S, Jacob ST and Ghoshal K: Down-regulation of micro-RNA-1 (miR-1) in lung cancer. Suppression of tumorigenic property of lung cancer cells and their sensitization to doxorubicin-induced apoptosis 31 by miR-1. J Biol Chem 283: 33394-33405, 2008.

5. Schickel R, Boyerinas B, Park SM and Peter ME: MicroRNAs:key players in the immune system, differentiation, tumorigenesis and cell death. Oncogene 27: 5959-5974, 2008.

6. Chhabra R, Dubey R and Saini N: Cooperative and individualistic functions of the microRNAs in the miR-23a 27a 24-2 cluster and its implication in human diseases. Mol Cancer 9: 232, 2010.

7. Zhang ZW, An Y and Teng CB: The roles of miR-17-92 cluster in mammal development and tumorigenesis. Yi Chuan 31: 1094-1100, 2009.

8. Di Leva G, Gasparini P, Piovan C, Nqankeu A, Garofalo M, Taccioli C, Iorio MV, Li M, Volinia S, Alder H, Nakamura T, Nuovo G, Liu Y, Nephew KP and Croce CM: MicroRNA cluster 221-222 and estrogen receptor alpha interactions in breast cancer. J Natl Cancer Inst 102: 706-721,2010.

9. Aqeilan RI, Calin GA and Croce CM: miR-15a and miR-16-1 in cancer: discovery, function and future perspectives. Cell Death Differ 17: 215-220, 2010.

10. Chiyomaru T, Enokida H, Tatarano S, Kawahara K, Uchida Y, Nishiyama K, Fujimura L, Kikkawa N, Seki N and Nakagawa M: miR-145 and miR-133a function as tumour suppressors and directly regulate FSCN1 expression in bladder cancer. Br J Cancer 102 883-891, 2010

11. Uchida Y, Chiyomaru T, Enokida H, Kawakami K, Tatarano S, Kawahara K, Nishiyama K, Seki N and Nakagawa M: MiR-133a induces apoptosis through direct regulation of GSTP1 in bladder cancer cell lines. Urol Oncol: Mar 9, 2011 (Epub ahead of print).

12. Datta J, Kutay H, Nasser MW, Nuovo GJ, Wang B, Majumder S, Liu CG, Volinia S, Croce CM, Schmittgen TD, Ghoshal K and Jacob ST: Methylation mediated silencing of MicroRNA-1 gene and its role in hepatocellular carcinogenesis. Cancer Res 68: 5049-5058, 2008.

13. Yan D, Dong Xda E, Chen X, Wang L, Lu C, Wang J, Qu J and Tu L: MicroRNA-1/206 targets c-Met and inhibits rhabdomyosarcoma development. J Biol Chem 284: 29596-29604, 2009.

14. Chiyomaru T, Enokida H, Kawakami K, Tatarano S, Uchida $Y$, Kawahara K, Nishiyama K, Seki N and Nakagawa M: Functional role of LASP1 in cell viability and its regulation by microRNAs in bladder cancer. Urol Oncol: Sep 14, 2011 (Epub ahead of print).

15. Yoshino H, Chiyomaru T, Enokida H, Kawakami K, Tatarano S, Nishiyama K, Nohata N, Seki N and Nakagawa M: The tumoursuppressive function of miR-1 and miR-133a targeting TAGLN2 in bladder cancer. Br J Cancer 104: 808-818, 2011.

16. Ichimi T, Enokida H, Okuno Y, Kunimoto R, Chiyomaru T, Kawamoto K, Kawahara K, Toki K, Kawakami K, Nishiyama K, Tsujimoto G, Nakagawa M and Seki N: Identification of novel microRNA targets based on microRNA signatures in bladder cancer. Int J Cancer 125: 345-352, 2009.

17. Zhang Y, Ye Y, Shen D, Jiang K, Zhang H, Sun W, Zhang J, Xu F, Cui $Z$ and Wang S: Identification of transgelin-2 as a biomarker of colorectal cancer by laser capture microdissection and quantitative proteome analysis. Cancer Sci 101: 523-529, 2010.

18. Nohata N, Hanazawa T, Kikkawa N, Sakurai D, Sasaki K, Chiyomaru T, Kawakami K, Yoshino Y, Enokida H, Nakagawa M, Okamoto Y and Seki N: Identification of novel molecular targets regulated by tumor suppressive $\mathrm{miR}-1 / \mathrm{miR}-133 \mathrm{a}$ in maxillary sinus squamous cell carcinoma. Int J Oncol 39: 1099-1107, 2011.
19. Kawakami K, Enokida H, Chiyomaru T, Tatarano S, Yoshino H, Kagara I, Gotanda T, Tachiwada T, Nishiyama K, Nohata N, Seki N and Nakagawa M: The functional significance of miR-1 and miR-133a in renal cell carcinoma. Eur J Cancer: Jul 9, 2011 (Epub ahead of print).

20. Kojima S, Chiyomaru T, Kawakami K, Yoshino H, Enokida H, Nohata N, Fuse M, Ichikawa T, Naya Y, Nakagawa M and Seki N: Tumour suppressors miR-1 and miR-133a target the oncogenic function of purine nucleoside phosphorylase (PNP) in prostate cancer. Br J Cancer 106: 405-413, 2012.

21. Sarver AL, French AJ, Borralho PM, Thayanithy V, Oberg AL, Silverstein KA, Morlan BW, Riska SM, Boardman LA, Cunningham JM, Subramanian S, Wang L, Smyrk TC, Rodrigues CM, Thibodeau SN and Steer CJ: Human colon cancer profiles show differential microRNA expression depending on mismatch repair status and are characteristic of undifferentiated proliferative states. BMC Cancer 9: 401, 2009.

22. Wong TS, Liu XB, Chung-Wai HA, Po-Wing YA, Wai-Man NR and Ignace WW.: Identification of pyruvate kinase type M2 as potential oncoprotein in squamous cell carcinoma of tongue through microRNA profiling. Int J Cancer 123: 251-257, 2008.

23. Rao PK, Missiaglia E, Shields L, Hyde G, Yuan B, Shepherd CJ, Shipley J and Lodish HF: Distinct roles for miR-1 and miR-133a in the proliferation and differentiation of rhambdomyosarcoma cells. FASEB J 24: 3427-3437, 2010.

24. Nohata N, Hanazawa T, Kikkawa N, Mutallip M, Fujimura L, Yoshino H, Kawakami K, Chiyomaru T, Enokida H, Nakagawa M, Okamoto Y and Seki N: Caveolin-1 mediates tumor cell migration and invasion and its regulation by miR-133a in head and neck squamous cell carcinoma. Int J Oncol 38: 209-217, 2011.

25. Mutallip M, Nohata N, Hanazawa T, Kikkawa N, Horiguchi S, Fujimura L, Kawakami K, Chiyomaru T, Enokida H, Nakagawa M, Okamoto Y and Seki N: Gultathione S-transferase P1 (GSTP1) suppresses cell apoptosis and its regulation by miR-133a in head and neck squamous cell carcinoma (HNSCC). Int J Mol Med 27: 345-352, 2011.

26. Jiang X, Kim HE, Shu H, Zhao Y, Zhang H, Kofron J, Donnelly J, Burns D, Nq SC, Rosenberg S and Wang X: Distinctive roles of PHAP proteins and prothymosin-alpha in a death regulatory pathway. Science 299: 223-226, 2003.

27. AbdelmohsenK,Lal A,KimHHandGorospe M:Posttranscriptional orchestration of an anti-apoptotic program by HuR. Cell Cycle 6: 1288-1292, 2007.

28. Sasaki H, Nonaka M, Fujii Y, Yamakawa Y, Fukai I, Kiriyama M and Sasaki M: Expression of the prothymosin- $\alpha$ gene as a prognostic factor in lung cancer. Surg Today 31: 936-938, 2001.

29. Wang M, Pan JY, Song GR, Chen HB, An LJ and Qu SX: Altered expression of estrogen receptor alpha and beta in advanced gastric adenocarcinoma: correlation with prothymosin alpha and clinicopathological parameters. Eur J Surg Oncol 33: 195-201, 2007.

30. Letsas KP, Frangou-Lazaridis M, Skyrlas A, Tsatsoulis A and Malamou-Mitsi V: Transcription factor-mediated proliferation and apoptosis in benign and malignant thyroid lesions. Pathol Int 55: 694-702, 2005.

31. Wu CG, Habib NA, Mitry RR, Reitsma PH, van Deventer SJ and Chamuleau RA: Overexpression of hepatic prothymosin alpha, a novel marker for human hepatocellular carcinoma. Br J Cancer 76: 1199-1204, 1997.

32. Gou LT, Tong AP, Yan F, Yuan Z, He F, Wang W, Zhou Y, Chen LJ, Tang $\mathrm{MH}$ and Yang JL: Altered protein-expressing profile in hPNAS4-induced apoptosis in A549 human lung adenocarcinoma cells. J Cell Biochem 108: 1211-1219, 2009.

33. Balakrishnan K, Verma D, O'Brien S, Kilpatrick JM, Chen Y, Tyler BF, Bickel S, Bantia S, Keating MJ, Kantarjian H, Ghandhi V and Ravandi F: Phase 2 and pharmacodynamic study of oral forodesine in patients with advanced, fludarabine-treated chronic lymphocytic leukemia. Blood 116: 886-892, 2010.

34. Alonso R, Lopez-Guerra M, Upshaw R, Bantia S, Smal C, Bontemps F, Manz C, Mehrling T, Villamor N, Campo E, Montserrat E and Colomer D: Forodesine has high antitumor activity in chronic lymphocytic leukemia and activates p53-independent mitochondrial apoptosis by induction of p73 and BIM. Blood 114: 1563-1575, 2009. 